\title{
CURRENT CLINICAL APPLICATIONS OF ADIPOSE-DERIVED STEM CELLS IN HUMANS AND ANIMALS
}

\author{
Claudia Dompe ${ }^{1}$, Grzegorz Wąsiatycz ${ }^{2}$, Paul Mozdziak³ ${ }^{3}$ Maurycy Jankowski, Bartosz Kempisty ${ }^{4,5,6}$
}

\begin{abstract}
Adipose derived stem cells are a type of mesenchymal stem cell that, because of their straightforward isolation procedure and ready availability, have been intensively studied in the recent years regarding their possible clinical applications. Additionally, ADSCs have the ability to differentiate into tri-germ lineages, as well as exhibit paracrine activity. Their capacity to differentiate into many different cell lineages such as osteocytes, adipocytes, neural cells, vascular endothelial cells, cardiomyocytes, pancreatic cells, and hepatocytes, has granted them a significant place in consideration for tissue engineering and for their application in regenerative medicine. Moreover, their endocrine activity has a great impact upon therapies as it grants immunosuppressive properties and low immunogenicity.
\end{abstract}

Running title: Clinical applications of ADSCs

Keywords: ADSCs, stem cells, research, clinical applications

\footnotetext{
${ }^{1}$ The School of Medicine, Medical Sciences and Nutrition, University of Aberdeen, UK

${ }^{2}$ Veterinary Center, Nicolaus Copernicus University in Torun, Torun, Poland.

${ }^{3}$ Physiology Graduate Program, North Carolina State University, Raleigh, North Carolina

${ }^{4}$ Department of Anatomy, Poznan University of Medical Sciences, Poznan, Poland

${ }^{5}$ Department of Histology and Embryology, Poznan University of Medical Sciences, Poznan, Poland

${ }^{6}$ Department of Obstetrics and Gynecology, University Hospital and Masaryk University, Brno, Czech Republic

* Correspondence: bkempisty@ump.edu.pl

Full list of author information is available at the end of article
} 


\section{Introduction}

The ability of stem cells to differentiate towards different cell lineages and constantly self-renewmakes them a promising tool in cell-based therapies such as tissue engineering and regenerative medicine [1]. The potential clinical application of stem cells remains highly significant and still not reduced to practice. Adipose derived stem cells (ADSCs) were firstly characterized in 2001, with first description of the adipose tissue as an effective source of mesenchymal progenitors.

ADSCs have similar characteristics as mesenchymal stem cells isolated from the bone marrow. Both have the ability to differentiate into adipogenic, osteogenic, chondrogenic and myogenic lineages. There are numerous benefits of obtaining stem cells from fat tissue, as compared with bone marrow. Firstly, stem cell isolation from the bone marrow is a very invasive and painful procedure, requiring the use of anaesthesia and yielding low numbers of viable cells upon processing [2]. Bone marrow-derived stem cells generally exhibitsignificant blood contamination, which leads to a proportional smaller number of stem cells. It has also beenobserved that large amounts of stem cells can be obtained from large quantities of fat tissue extracted both by aspiration and excision [3].

ADSCs can be obtained by both liposuction and excision of adipose tissue, which is often discarded aftersurgery, with the former method described as the better method of their preparation for storage. In fact, liposuction sample analysis does not show a significant loss of preadipocytes which shows it does not significantly damage the stroma [4]. Hence, a large number of ADSCs can be harvested from adipose tissue and do not need to be expanded and to proliferate in vitro, which translates to obtaining cells that provide more predictable results [5]. ADSC advantages over bone marrow stem cells, which, despite exhibiting similar differentiation potential, showed less in vitro proliferation capacity and proliferative senescence [6].

\section{Isolation of SVF}

The stromal vascular fraction (SVF) includes a variety of cell lineages, such as: mesenchymal stem cells, endothelial precursor cells and endothelial cells, T regulatory cells, macrophages, smooth muscle cells, as well as pericytes and preadipocytes. For this reason, the SVF is the source of primary adipocytes $[7,8]$. The SVF can be isolated from the adipose tissue through different techniques, such as enzymatic digestion.

Two fractions can be obtained from the adipose tissue isolate based upon cell density. The separation can be enhanced by density-based centrifugation employing compounds such as Percoll, gravity-based phase separation, and filtration that leaves mature adipocyte on the surface and the aqueous fraction at the bottom [9]. Filtration will be more precise as it can specifically isolate cells based on size, while centrifugation will pellet all the cells [10]. The aqueous fraction is where the SVF is found, which is the source of ADSCs [9]. There are two hurdles ofconventional isolation. Firstly, conventional isolation not only requires the infrastructure and equipment that are not available to every healthcare facility, but also, because of the presence of collagenase in the product, which is required to process the crude samples, may provide a regulatory hurdle [11,9]. A non-enzymatic methods of SVF isolation, may be mechanical agitation, which bases on breaking down the adipose tissue allowing the release stromal cells. Following washing and shaking of the lipoaspirate, centrifugation is the next important step, required in both methods for concentration of stem cells. The agitation isolation technique reduces the regulatory burden compared to collagenase-based isolation, but it also prevents contamination when the cells are immediately administrated to a patient [12]. However, ADSCs isolated using agitation remain tightly bound by collagen-based extracellular matrix, resulting in a poor cell yield is much lower compared to conventional collagenase isolation $[12,13]$. Through adherence to cell culture dishes, ADSCs can be isolated and secondly expanded in vitro [1]. ADSCs can be preserved in a media of foetal bovine serum and dimethyl sulfoxide and, contrary to other MSCs, they do not lose their ability to differentiate and proliferate [2].

\section{Fat grafting and tumorigenesis}

Fat grafting is a common procedure which can be harnessed in breast reconstruction, both after cancer treatment and for breast augmentation, in the treatment of burn scars and post-traumatic malformations, rejuvenation, as well as treatment of other conditions [3]. ADSC have been widely used in fat grafting enrichment or augmentation of various soft tissue defects.

Regarding breast augmentation, autologous fat grafting has been preferred over other techniques for many reasons, such as its low cost, availability and low rates of allergenicity and immunogenicity [4]. Moreover, another application of fat graft enrichment that showed promising clinicalresults is in patients with craniofacial microsomia [5].

However, fat grafting has been observed to show high risks of reabsorption, which can vary from $25 \%$ to $80 \%$ [3], necrosis, leading to low survival chances and low volume of maintenance [6]. Multiple studies have come in support of the idea that addition of ADSCs promotes graft retention and development of new vasculature[4]. The efficacy of ADSC enrichment is attributed to the expression of different paracrine and growth factors, such as VEGF and HGF, which promote angiogenesis, and IGF-1, which is an antiapoptotic factor and promotes cells differ- 
entiation [4]. Moreover, the cooperation of ADSCs with other factors can provide further benefits. In fact, vascular endothelial growth factor-transduced ADSCs showed high capillary density, improving neovascularization [7]. ADSCs are effective not only in cosmetic breast augmentation [8], where their use proved to be highly effective in a study involving 40 patients, but can also be harnessed in breast reconstruction following breast resection [9]. Despite its significant advantages in the field of tissue augmentation, ADSC graft enrichment needs to be used carefully after breast cancer as it may increase the proliferation and metastasis of tumour cells $[10,11]$. Furthermore, SVF enrichment employed in breast augmentation was observed to be more efficient in cases following mastectomy rather than in cosmetic corrections [12]. Additionally, studies showed that ADSCs have an effect on active, but not on resting cancer cells making it important on a precautionary basis, to perform a reconstructive therapy with ASC-augmented fat only after complete establishment of cancer remission $[13,14]$. Novel methods of injection of adipose tissue for soft tissue augmentation are being studied to enhance the survival potential of ADSCs, e.g. cell assisted lipo-transfer (CAL) [15]. Few studies came in support of the benefits of CAL, which combines SVF isolated from one half of a lipoaspirate with other half of lipoaspirate not only in breast enhancement but also in people with facial microsomia [15]. Other studies support the efficacy of CAL $[16,17]$ but Peltonemi et al. failed to demonstrate a beneficial effect of fat graft enrichment consistent with the loss of regenerative potential of ADSCs following long enzymatic digestions [18].

\section{Bone regeneration}

In normal circumstances, bone tissue has the ability to self-renew and to generate new vascular tissue. In certain conditions, such as trauma, poor bone formation or the removal of cancer tissue, bone cells lack regenerativecapacity. Many techniques to enhance bone repair already exists, but other than being expensive and having a risk of morbidity at donor site [19] or risk of rejection [20]; they all lack progenitor osteogenic stem cells. The osteogenic potential of ADSCs has opened new prospects and horizons, with multiple studies showing the success involved in bone tissue engineering techniques and bone regeneration. The beneficial effects of the use of ADSC in bone regeneration are not only seen in bone tissue augmentation, but also in their ability to upregulate the release of growth factors and cytokines that provide anti-inflammatory and angiogenic properties [21]. Moreover, oppositely to MSCs, ADSC differentiation into bone tissue upon isolation needs induction, which can be directed by different stimuli, such as a specific culture media, the use of growth factors, and mechanical factors [22].
Different cases of bone regeneration showed positive results following treatment with ADSCs. In a study of the treatment of tibial defects in rabbits, the subjects were treated with hydroxyapatiteautologous ADSC constructssuggesting that bone reparation was promoted by the recruitment of resident progenitor cells [23]. Moreover, ADSCs were directly injected into the location of a bone defect in order to regenerate a 10 -mm-diameter fault in the pig mandibula. After surgery, an acceleration in the bone healing process was observed after only two weeks, with the defect was almost entirely recoveredafter four weeks [24]. The ability of ADSCs to help bone formation and regeneration was also observed in human cases. A large mandibular resection was replaced with a scaffold of recombinant human bone morphogenetic protein-2 (BMP-2) and ADSCs. This technique allowed rehabilitation and guaranteed a successful dental implant [25]. Furthermore, the use of BMP-2 was proven to be able to induce VSF to generate ectopic bone tissue [26].

Another important application of the ability of ADSC to induce osteogenesis is cranioplasty. In the treatment of four patients with different types of cranial defects, a combination of beta-tricalcium phosphate and autologous adipose-derived stem cells showed positiveresults. Ossification revealed a positive outcome while showing no side effects [27]. Moreover, the treatment of a calvarial defect upon trauma in a girl with a combination of ADSCs and iliac crest resulted in new bone development and calvarial continuity [28].

The interest in the potentiality of ADSC in orthopaedic procedure is presently being investigated. The safety and feasibility of ADSC application provides a promising solution to invasive and risky procedures.

\section{Cardiovascular application}

Different studies have investigated the potential of ADSCs in cardiovascular and myocardial tissue engineering. Heart infarction upon ischemic heart disease is one of the major conditions causing hospitalization and death of patients in the world. The only existing way of recovering from ischemic heart disease is transplantation, which is an invasive and risky procedure. ADSCs provide a potential therapy for ischemic heart disease because they have the ability to differentiate into cardiomyocytes, to maintain the presence of existing cardiovascular cells by the release of antiapoptotic factors. Although the paracrine effects of ADSCs are greater than the ones involved in tissue regeneration, ADSCs can stimulate angiogenesis. Multiple studies proved the positive efficacy of ADSCs application in the treatment of post myocardial infarction. In a study, during the recovery of pigs upon myocardial infarction, the animals were intracoronarily administrated with ADSCs. In the following four weeks, it was possible to 
observe improvements in the remodelling and functions of the heart $[29,30]$.

The main focus in the treatment of a post ischemic injury is neovascularization, which is promoted by two major processes: vasculo-genesis and angiogenesis [31]. Neovascularization can be enhanced by ADSCs. The differentiation of ADSCs into epithelial cells and smooth muscle cells leads to an increased vascularization of the area, preventing the risk of apoptosis of the cardiomyocytes [32]. The increased rate of survival of the cells is also induced by the ability of ADSCsto release paracrine factors, such as vascular endothelial growth factor (VEGF) [33]. VEGF can also activate cardiac stem cells to increase cardio-myogenesis. In fact, ADSCs release multiple angiogenic and antiapoptotic factors such asVEGF and hepatocyte growth factor (HGF) [29].

Moreover, studies have proved that rabbit ADSCs can differentiate into cardiomyocytes in vitro when treated with 5-azacytidine (5-aza), a DNA methyltransferase inhibitor, which was not effective in humans [34]. Cardiomyogenic differentiation in human ADSC was obtained with the co-culture of ADSC with rat cardiomyocytes, which resulted in formation of gap junctions and promotion of $\mathrm{Ca} 2+$ oscillations from the sarcoplasmic reticulum [30].

Moreover, compared to stem cells obtained from other adipose tissue, ADSCs isolated specifically from cardiac fat tissue in anin vitromodel of mouse myocardial infarction showed greater differentiation potential. These cells had a high density of markers for endothelial, vascular smooth muscle cells and cardiomyocytes and showed greater potential for the use in infarction recovery [35]. Moreover, the proliferation of ADSCs in vivo and their expression of cardiac cells markers can be increased by supplementing these cells with factors usually released by cardiomyocytes such as sarcomeric $\alpha$-actinin, desmin, and cardiac troponin I [36].

Upon studies that proved the cardiomyogenic potential of ADSC, Savi et al. observed how local injection of stem cells in patients that suffered from myocardial infarction, along with microspheres that constantly release HGF and insulin-like growth factors (IGF-1), resulted in a greater growth in the damaged area compared to any other growth factor [37].

Finally, it was suggested that the ability of ADSC to generate extracellular matrix could be used for tissue engineered heart valves (TEHVs). When cultivated and seeded with endothelial cells derived from ADSC, heart valves showed a cell distribution that was endothelialized and composed of glycosaminoglycans and collagen [38]. Along with the production of collagen and elastin, their ability to respond biophysical and biochemical stimuli increases their amazing potential for cardiovascular tissue engineering [39].

\section{Immune mediated diseases}

ADSCs have been proposed asa possible solution for the treatment of immune disorders such as Crohn's disease, rheumatoid arthritis and graftversus-host disease. The adaptive immune system relies on the recognition of foreign or non-foreign antigens to prevent the organism from undergoing infection. At times this biological network is flawed and is subjected to impairment in self-tolerance. In the case of rheumatoid arthritis, a decrease in self-tolerance leads to an autoimmunity to components of the joints rich in collagen, activating autoreactive $\mathrm{T}$ cells and leading to bone destruction [40]. Gonzalez-Rey et al. showed that ADSCs have immunosuppressant properties, regulating immune tolerance and limiting the action of T cells. Moreover, when administered to patients, ADSCs lowered the response in proliferation and the release of cytokines [41]. For instance, the treatment of collagen-induced arthritis mice models with ADSCs not only helped modulating the immune response, but also showed a diminished bone loss, and an increase in osteoclastogenesis and the number of osteoclast precursors $[42,43]$. A further study suggested that the intralymphatic administration of ADSCs is a very effective treatment for arthritis. Intralymphatic administration could be a prospective highly effective way of administration for treatments of other auto-immune diseases [44].

Although different studies have shown the capability of ADSCs in the treatment diseases such as Crohn's disease and graft-versus-host disease (GVHD), much more research needs to be done to develop a proper method. Crohn's disease is a chronic bowel disease caused by a loss in self-tolerance to mucosal antigens, which leads to a greater production of cytokines and chemokines, causing tissue damage [45]. A study showed that the injection of human ADSCs in mice at the onset of the induced bowel disease improved clinical and histopathologic gravity of the disease. Although the mechanism through which they act was not established nor well understood, it was observed that hADSC diminished the inflammatory response. hADSC down-regulated the release of mediators and increased the production of IL-2 [46]. Regarding the treatment of patients with perianal fistula affected by Crohn's disease a study showed positive results [47].

Furthermore, Fang et al. carried a study on patients with acute steroid refractory GVHD and the use of ADSCs seemed promising. However, the low number of patients only shows positive effects and the need of future research but cannot ensure the clinical efficiency [48].

Another study proved how ADSCs transplant, both allogenic and syngeneic, in mice models with induced autoimmune thyroiditis showed improved therapeutic 
effects. The amount of antithyroglobulin autoantibodies and the inflammatory response were decreased, with the T helper cells balance re-established [49].

\section{Future applications}

The variety of ADSCapplications in human medicine keeps expanding, with multiple ongoing parallel clinical trials creating new treatement opportunities. The numerous recent discoveries and developments involving ADSCs are nowadays leading to solutions for therapies closer to medical standards.

The technological development of therapies involving ADSCs requires a better understanding of their biology and pathways of action. This continuous endeavour of clarifying their mechanism will allow therapies to act on specific targets and may permit control of ADSCdifferentiation. Currently, there are few technologies that direct the differentiation of ADSCs towards the development of the tissue of interest, such different cultivation methods, genetic manipulation, epigenetic control and the use of different scaffolds [50,51]. 3D cultured and spheroid forming MSCs have, in fact, showed great advantages in many therapies of animal disease models, promoting differentiation and release of trophic factors [52]. Moreover, the manipulation of the epigenetics of ADSCs may be done before or after they have been administered to a patient, with its advantages needing further consideration. While epigenetic modulation may be harnessed to treat some diseases, it could also result in harming the patient, making patients' safety the potentialfocus offuture research [50].

There remains a wide range ofADSC applications, and potential therapies have given new hopes for yet untreatable conditions, or those curable with very invasive surgeries, or requiring constant care. For example, in paediatric brainstem glioma, an inoperable brain tumour, and a study suggested the ability of ADSCs as a great tool for cell-based gene therapy [53]. Another study noted the success of ADSCs gene therapy in the case of X-linked retinoschisis. ADSC were genetically modified to secrete extracellular cell adhesion protein missing when in patients affected by the disease. The delivery of the protein through ADSCs restored the insufficiencies [54].

Furthermore, the application of ADSCs can be extensive not only in the medical field. Some studies have provided proof that adult stem cells may be a successful source for somatic cell cloning which may ultimately lead to an improvement of livestock meat quality through the production of transgenic animals. Due to their great adaptability, the possibility of harnessing ADSC even in this field would need further research [55].

Finally, ADSCs may be used as a diagnostic tool. Upon isolation ADSC may be observed for heterogenicity in patients and a database for future healthcare could be organized based on age, weight, background, ethnicity or lifestyle [52].

\section{Conclusions}

Adipose tissue has been subject of various studies involving many different fields and it is believed to be a useful source of stem cells due to its great availability and relatively easy isolation compared to bone marrow derived stem cells [2]. ADSCs have the ability to differentiate towards different cell lineages, such as osteocytes, adipocytes, neural cells, vascular endothelial cells, cardiomyocytes, pancreatic cells, and hepatocytes, with possibility of directing this differentiation increasing the chances of ADSC clinical applications. ADSCs have been widely used in therapies which involved the necessity of tissue augmentation, such as fat grafting. Moreover, multiple applications have been observed in bone regeneration therapies. The positive results were obtained not only due to the ability of ADSCs to differentiate into osteocytes, but also because of their paracrine activity. In fact, their paracrine activity was proven to have positive effects on the treatment of some cardiovascular pathologies and diseases affecting the immune system.

Because of recent studies and discoveries on ADSCs, new perspectives of their application are constantly found. However, much further research is needed to allow to use all of the advantages of these cells and fully understand the potential of ADSCs.

\section{Ethical approval}

The conducted research is not related to either human or animal use.

\section{Corresponding author}

Bartosz Kempisty, Department of Anatomy, Poznan University of Medical Sciences, 6 Święcickiego St., 60-781 Poznań, Poland, Tel./Fax: +48 61 8546565, e-mail: bkempisty@ump.edu.pl.

\section{Conflict of interest statement}

The authors declare they have no conflict of interest.

\section{References}

1. Astori G, Vignati F, Bardelli S, Tubio M, Gola M, Albertini V, Bambi F, Scali G, Castelli D, Rasini V, Soldati G, Moccetti T. "In vitro" and multicolor phenotypic characterization of cell subpopulations identified in fresh human adipose tissue stromal vascular fraction and in the derived mesenchymal stem cells. J Transl Med. 2007;5; DOI:10.1186/1479-5876-5-55.

2. Miyagi-Shiohira C, Kurima K, Kobayashi N, Saitoh I, Watanabe M, Noguchi Y, Matsushita M, Noguchi H. Cryopreservation of Adipose-Derived Mesenchymal Stem Cells. Cell Med. 2015;8:3-7; DOI:10.3727/215517915x689100.

3. Kølle SFT, Fischer-Nielsen A, Mathiasen AB, Elberg JJ, Oliveri RS, Glovinski P V., Kastrup J, Kirchhoff M, Rasmussen BS, Talman MLM, Thomsen C, Dickmeiss E, Drzewiecki KT. Enrichment of autologous fat grafts with ex-vivo expanded adipose tissue-derived stem cells for graft survival: A randomised placebo-controlled trial. Lancet. 2013;382:1113-20; DOI:10.1016/S0140-6736(13)61410-5

4. Zhu M, Zhou Z, Chen Y, Schreiber R, Ransom JT, Fraser JK, Hedrick MH, Pinkernell K, Kuo HC. Supplementation of fat grafts with adipose-derived regenerative cells improves long-term graft retention. Ann Plast Surg. 2010;64:222-8; DOI:10.1097/SAP.0b013e31819ae05c.

5. Tanikawa DYS, Aguena M, Bueno DF, Passos-Bueno MR, Alonso N. Fat grafts supplemented with adipose-derived stromal cells in the rehabilitation of patients with craniofacial microsomia. PlastReconstr Surg. 2013;132:141-52; D0I:10.1097/PRS.0b013e3182910a82.

6. Šmahel J. Experimental implantation of adipose tissue fragments. Br J Plast Surg. 1989;42:207-11; DOI:10.1016/0007-1226(89)90205-1.

7. Lu F, Li J, Gao J, Ogawa R, Ou C, Yang B, Fu B. Improvement of the survival of human autologous fat transplantation by using VEGF-transfected 
adipose-derived stem cells. PlastReconstr Surg. 2009;124:1437-46; DOI:10.1097/PRS.0b013e3181babbb6.

8. Kamakura T, Ito K. Autologous cell-enriched fat grafting for breast augmentation. Aesthetic Plast Surg. 2011;35:1022-30; D0I:10.1007/ s00266-011-9727-7.

9. Tsekouras A, Mantas D, Tsilimigras DI, Ntanasis-Stathopoulos I, Kontos M, Zografos GC. Adipose-derived stem cells for breast reconstruction after breast surgery - preliminary results. Case Reports PlastSurg Hand Surg. 2017;4:35-41; DOI:10.1080/23320885.2017.1316201.

10. Mandel K, Yang Y, Schambach A, Glage S, Otte A, Hass R. Mesenchymal stem cells directly interact with breast cancer cells and promote tumor cell growth in vitro and in vivo. Stem Cells Dev. 2013;22:3114-27; DOI:10.1089/scd.2013.0249.

11. Karnoub AE, Dash AB, Vo AP, Sullivan A, Brooks MW, Bell GW, Richardson AL, Polyak K, Tubo R, Weinberg RA. Mesenchymal stem cells within tumour stroma promote breast cancer metastasis. Nature. 2007;449:55763; DOI:10.1038/nature06188.

12. Chatterjee S, Laliberte M, Blelloch S, Ratanshi I, Safneck J, Buchel E, Raouf A. Adipose-derived stromal vascular fraction differentially expands breast progenitors in tissue adjacent to tumors compared to healthy breast tissue. PlastReconstr Surg. 2015;136:e414-25; DOI:10.1097/ PRS.0000000000001635.

13. Zimmerlin L, Donnenberg AD, Rubin JP, Basse P, Landreneau RJ, Donnenberg VS. Studies of the Interaction Between Adipose-Derived Stem Cells and Breast Cancer Cells from Clinical Isolates n.d.; DOI:10.1089/ ten.tea.2010.0248.

14. Han S, Sun HM, Hwang KC, Kim SW. Adipose-derived stromal vascular fraction cells: Update on clinical utility and efficacy. Crit Rev Eukaryot Gene Expr. 2015;25:145-52; DOI:10.1615/ CritRevEukaryotGeneExpr.2015013057.

15. Matsumoto D, Sato K, Gonda K, Takaki Y, Shigeura T, Sato T, Aiba-Kojima E, Iizuka F, Inoue K, Suga H, Yoshimura K. Cell-Assisted Lipotransfer: Supportive Use of Human Adipose-Derived Cells for Soft Tissue Augmentation with Lipoinjection. n.d.

16. Kakudo N, Tanaka Y, Morimoto N, Ogawa T, Kushida S, Hara T, Kusumoto K. Adipose-derived regenerative cell (ADRC)-enriched fat grafting: Optimal cell concentration and effects on grafted fat characteristics. J Trans Med. 2013;11; DOI:10.1186/1479-5876-11-254.

17. Sterodimas A, De Faria J, Nicaretta B, Boriani F. Autologous fat transplantation versus adipose-derived stem cell-enriched lipografts: A study. Aesthetic Surg J. 2011;31:682-93; DOI:10.1177/1090820X11415976.

18. Peltoniemi HH, Salmi A, Miettinen S, Mannerström B, Saariniemi K, Mikkonen R, Kuokkanen H, Herold C. Stem cell enrichment does not warrant a higher graft survival in lipofilling of the breast: A prospective comparative study. J PlastReconstr Aesthetic Surg. 2013;66:1494-503; DOI:10.1016/j.bjps.2013.06.002.

19. Oryan A, Alidadi S, Moshiri A, Maffulli N. Bone regenerative medicine: classic options, novel strategies, and future directions. J OrthopSurg Res. 2014:9:18; DOI:10.1186/1749-799X-9-18.

20. DeOrio JK, Farber DC. Morbidity associated with anterior iliac crest bone grafting in foot and ankle surgery. Foot Ankle Int. 2005;26:147-51; DOI:10.1177/107110070502600206.

21. Frese L, Dijkman PE, Hoerstrup SP. Adipose Tissue-Derived Stem Cells in Regenerative Medicine. Transfus Med Hemother. 2016;43:268-74; DOI:10.1159/000448180.

22. Morcos MW, Al-Jallad H, Hamdy R. Comprehensive Review of Adipose Stem Cells and Their Implication in Distraction Osteogenesis and Bone Regeneration. Biomed Res Int. 2015;2015; DOI:10.1155/2015/842975.

23. Arrigoni E, de Girolamo L, Di Giancamillo A, Stanco D, Dellavia C, Carnelli D, Campagnol M, Domeneghini C, Brini AT. Adipose-derived stem cells and rabbit bone regeneration: histomorphometric, immunohistochemical and mechanical characterization. J Orthop Sci. 2013;18:331-9; DOI:10.1007/s00776-012-0349-y.

24. Wilson SM, Goldwasser MS, Clark SG, Monaco E, Bionaz M, Hurley WL, Rodriguez-Zas S, Feng L, Dymon Z, Wheeler MB. Adipose-derived mesenchymal stem cells enhance healing of mandibular defects in the ramus of swine. J Oral Maxillofac Surg. 2012;70; DOI:10.1016/j. joms.2011.10.029.

25. Sándor GK, Tuovinen VJ, Wolff J, Patrikoski M, Jokinen J, Nieminen E, Mannerström B, Lappalainen OP, Seppänen R, Miettinen S. Adipose stem cell tissue-engineered construct used to treat large anterior mandibular defect: A case report and review of the clinical application of good manufacturing practice-level adipose stem cells for bone regeneration. J Oral Maxillofac Surg. 2013;71:938-50; DOI:10.1016/j.joms.2012.11.014.

26. Mehrkens A, Saxer F, Güven S, Hoffmann W, Müller AM, Jakob M, Weber FE, Martin I, Scherberich A. Intraoperative engineering of osteogenic grafts combining freshly harvested, human adipose-derived cells and physiological doses of bone morphogenetic protein-2. Eur Cells Mater. 2012;24:308-19; DOI:10.22203/eCM.v024a22.
27. Thesleff T, Lehtimäki K, Niskakangas T, Mannerström B, Miettinen S, Suuronen R, Öhman J. Cranioplasty with adipose-derived stem cells and biomaterial: a novel method for cranial reconstruction. Neurosurgery. 2011;68:1535-40; DOI:10.1227/NEU.0b013e31820ee24e.

28. Lendeckel S, Jödicke A, Christophis P, Heidinger K, Wolff J, Fraser JK, Hedrick MH, Berthold L, Howaldt HP. Autologous stem cells (adipose) and fibrin glue used to treat widespread traumatic calvarial defects: Case report. J Cranio-Maxillofacial Surg. 2004;32:370-3; DOI:10.1016/j. jcms.2004.06.002

29. Rehman J, Traktuev D, Li J, Merfeld-Clauss S, Temm-Grove CJ, Bovenkerk JE, Pell CL, Johnstone BH, Considine R V., March KL. Secretion of Angiogenic and Antiapoptotic Factors by Human Adipose Stromal Cells. Circulation. 2004;109:1292-8; DOI:10.1161/01.CIR.0000121425.42966.F1.

30. Choi YS, Dusting GJ, Stubbs S, Arunothayaraj S, Han XL, Collas P, Morrison WA, Dilley RJ. Differentiation of human adipose-derived stem cells into beating cardiomyocytes. J Cell Mol Med. 2010;14:878-89; DOI:10.1111/j.1582-4934.2010.01009.x.

31. Miranville A, Heeschen C, Sengenès C, Curat CA, Busse R, Bouloumié A. Improvement of postnatal neovascularization by human adipose tissue-derived stem cells. Circulation. 2004;110:349-55; DOI:10.1161/01. CIR.0000135466.16823.D0.

32. Valina C, Pinkernell K, Song YH, Bai X, Sadat S, Campeau RJ, Le Jemtel TH, Alt E. Intracoronary administration of autologous adipose tissue-derived stem cells improves left ventricular function, perfusion, and remodelling after acute myocardial infarction. Eur Heart J. 2007;28:2667-77; DOI:10.1093/eurheartj/ehm426.

33. Planat-Benard V, Silvestre JS, Cousin B, André M, Nibbelink M, Tamarat R, Clergue M, Manneville C, Saillan-Barreau C, Duriez M, Tedgui A, Levy B, Pénicaud L, Casteilla L. Plasticity of Human Adipose Lineage Cells Toward Endothelial Cells: Physiological and Therapeutic Perspectives. Circulation. 2004;109:656-63; DOI:10.1161/01. CIR.0000114522.38265.61.

34. Rangappa S, Fen C, Lee EH, Bongso A, Sim EKW, Wei EKS. Transformation of adult mesenchymal stem cells isolated from the fatty tissue into cardiomyocytes. Ann Thorac Surg. 2003;75:775-9; DOI:10.1016/ s0003-4975(02)04568-x.

35. Nagata H, Ii M, Kohbayashi E, Hoshiga M, Hanafusa T, Asahi M. Cardiac Adipose-Derived Stem Cells Exhibit High Differentiation Potential to Cardiovascular Cells in C57BL/6 Mice. Stem Cells Transl Med. 2016;5:141-51; DOI:10.5966/sctm.2015-0083.

36. Gaustad KG, Boquest AC, Anderson BE, Gerdes AM, Collas P. Differentiation of human adipose tissue stem cells using extracts of rat cardiomyocytes. BiochemBiophys Res Commun. 2004;314:420-7; DOI:10.1016/j. bbrc.2003.12.109.

37. Savi M, Bocchi L, Fiumana E, Karam JP, Frati C, Bonafé F, Cavalli S, Morselli PG, Guarnieri C, Caldarera CM, Muscari C, Montero-Menei CN, Stilli D, Quaini F, Musso E. Enhanced engraftment and repairing ability of human adipose-derived stem cells, conveyed by pharmacologically active microcarriers continuously releasing HGF and IGF-1, in healing myocardial infarction in rats. J Biomed Mater Res - Part A. 2015;103:3012-25; DOI:10.1002/jbm.a.35442.

38. L F, B S. Adipose Derived Tissue Engineered Heart Valve. J Tissue Sci Eng 2015;06; DOI:10.4172/2157-7552.1000156.

39. Colazzo F, Sarathchandra P, Smolenski RT, Chester AH, Tseng YT, Czernuszka JT, Yacoub MH, Taylor PM. Extracellular matrix production by adipose-derived stem cells: Implications for heart valve tissue engineering. Biomaterials. 2011;32:119-27; DOI:10.1016/j. biomaterials.2010.09.003.

40. Firestein GS. Evolving concepts of rheumatoid arthritis. Nature 2003;423:356-61; DOI:10.1038/nature01661.

41. Gonzalez-Rey E, Gonzalez MA, Varela N, O'Valle F, Hernandez-Cortes P, Rico L, Büscher D, Delgado M. Human adipose-derived mesenchymal stem cells reduce inflammatory and $\mathrm{T}$ cell responses and induce regulatory $\mathrm{T}$ cells in vitro in rheumatoid arthritis. Ann Rheum Dis. 2010;69:241-8; DOI:10.1136/ard.2008.101881.

42. Garimella MG, Kour S, Piprode V, Mittal M, Kumar A, Rani L, Pote ST, Mishra GC, Chattopadhyay N, Wani MR. Adipose-Derived Mesenchymal Stem Cells Prevent Systemic Bone Loss in Collagen-Induced Arthritis. J Immunol. 2015;195:5136-48; DOI:10.4049/jimmunol.1500332.

43. Tanaka K, Hashizume M, Mihara M, Yoshida H, Suzuki M, Matsumoto Y. Anti-interleukin-6 receptor antibody prevents systemic bone mass loss via reducing the number of osteoclast precursors in bone marrow in a collagen-induced arthritis model. Clin Exp Immunol. 2014;175:172-80; DOI:10.1111/cei.12201.

44. Mancheño-Corvo P, Lopez-Santalla M, Menta R, DelaRosa O, Mulero F, Rio B del, Ramirez C, Büscher D, Bueren JA, Lopez-Belmonte J, Dalemans W, Garin MI, Lombardo E. Intralymphatic administration of adipose mesenchymal stem cells reduces the severity of collagen-induced experimental arthritis. Front Immunol. 2017;8; DOI:10.3389/fimmu.2017.00462. 
45. Bouma G, Strober W. The immunological and genetic basis of inflammatory bowel disease. Nat Rev Immunol. 2003;3:521-33; DOI:10.1038/ nri1132.

46. González MA, Gonzalez-Rey E, Rico L, Büscher D, Delgado M. Adipose-Derived Mesenchymal Stem Cells Alleviate Experimental Colitis by Inhibiting Inflammatory and Autoimmune Responses. Gastroenterology. 2009;136:978-89; DOI:10.1053/j.gastro.2008.11.041.

47. Panés J, García-Olmo D, Van Assche G, Colombel JF, Reinisch W, Baumgart DC, Dignass A, Nachury M, Ferrante M, Kazemi-Shirazi L, Grimaud JC, de la Portilla F, Goldin E, Richard MP, Leselbaum A, Danese S. Expanded allogeneic adipose-derived mesenchymal stem cells (Cx601) for complex perianal fistulas in Crohn's disease: a phase 3 randomised, double-blind controlled trial. Lancet. 2016;388:1281-90; DOI:10.1016/ S0140-6736(16)31203-X.

48. Fang B, Song Y, Liao L, Zhang Y, Zhao RC. Favorable Response to Human Adipose Tissue-Derived Mesenchymal Stem Cells in Steroid-Refractory Acute Graft-Versus-Host Disease. Transplant Proc. 2007;39:3358-62; DOI:10.1016/j.transproceed.2007.08.103.

49. Choi EW, Shin IS, Park SY, Yoon EJ, Kang SK, Ra JC, Hong SH. Characteristics of mouse adipose tissue-derived stem cells and therapeutic comparisons between syngeneic and allogeneic adipose tissue-derived stem cell transplantation in experimental autoimmune thyroiditis. Cell Transplant. 2014;23:873-87; DOI:10.3727/096368913X664586.

50. Wang X, Wang Z, Wang Q, Liang H, Liu D. Trichostatin A and vorinostat promote adipogenic differentiation through H3K9 acetylation and dimethylation. Res Vet Sci. 2019; DOI:10.1016/j.rvsc.2019.09.002.

51. Gimble JM, Katz AJ, Bunnell BA. This Review is part of a thematic series on the Pathobiology of Obesity, which includes the following articles: Adipose-Derived Stem Cells for Regenerative Medicine Adipose-Derived Stem Cells for Regenerative Medicine 2007; DOI:10.1161/01. RES.0000265074.83288.09.

52. Han HW, Asano S, Hsu SH. Cellular spheroids of mesenchymal stem cells and their perspectives in future healthcare. Appl Sci. 2019;9; DOI:10.3390/app9040627.

53. Choi SA, Lee YE, Kwak PA, Lee JY, Kim SS, Lee SJ, Phi JH, Wang KC, Song J, Song SH, Joo KM, Kim SK. Clinically applicable human adipose tissue-derived mesenchymal stem cells delivering therapeutic genes to brainstem gliomas. Cancer Gene Ther. 2015;22:302-11; DOI:10.1038/cgt.2015.25.

54. Bashar AE, Metcalfe AL, Viringipurampeer IA, Yanai A, Gregory-Evans $\mathrm{CY}$, Gregory-Evans K. An ex vivo gene therapy approach in X-linked retinoschisis. Mol Vis. 2016;22:718-33.

55. Miana VV, Prieto González EA. Adipose tissue stem cells in regenerative medicine. Ecancermedicalscience. 2018;12; DOI:10.3332/ ecancer.2018.822 